\title{
Mechanisms of arsenite oxidation and arsenate adsorption by a poorly crystalline manganese oxide in the presence of low molecular weight organic acids
}

\author{
Mengyu Liang ${ }^{1,2}$, Huaming Guo ${ }^{1,2, *}$, and Wei Xiu ${ }^{1}$ \\ ${ }^{1}$ State Key Laboratory of Biogeology and Environmental Geology, China University of Geosciences, \\ Beijing 100083, P.R. China \\ ${ }^{2}$ School of Water Resources and Environment, China University of Geosciences (Beijing), Beijing \\ 100083, P.R. China
}

\begin{abstract}
Manganese oxides are considered as one of the effective oxides capable of oxidizing arsenite and reduce the toxicity of arsenic. Since low molecular weight organic acids (LMWOAs) commonly found in nature can act as reducing and chelating agents for manganese oxides, it is particularly important to investigate how these organic acids with different numbers of carboxyl groups like citrate and EDTA affect oxidation and adsorption of arsenic by manganese oxides. In this study, low $\mathrm{As}(\mathrm{V})$ adsorption on manganese oxide is slightly enhanced by citrate and EDTA, which results from the increase in active sites via reduction of manganese oxide by LMWOAs. However, citrate and EDTA have different effects on the oxidation of $\mathrm{As}(\mathrm{III}) . \mathrm{Mn}^{\mathrm{III} / \mathrm{II}}$ citrate autocatalytic cycle as a manganesebased redox system decreases As(III) oxidation rate, but EDTA does not yield autocatalysis, which slightly increases the oxidation rate of As(III). Reduction of manganese oxide by EDTA and chelation between Mn(II) and EDTA lead to exposure of more active sites. Our research highlights the different effects of low molecular weight organic acids on the reactions between arsenic and manganese oxide.
\end{abstract}

\section{Introduction}

$\mathrm{Mn}^{\mathrm{III} / \mathrm{IV}}$ (hydr)oxides are highly reactive minerals, widely occurring in marine, riverine, and lacustrine systems [1]. Due to their strong oxidation and adsorption capacities, manganese oxides are widely investigated for their controls on the transformation of different components in the environment, especially various trace metals and metalloids (As, $\mathrm{Cr}, \mathrm{Cu}, \mathrm{Pb}$, etc). Low molecular weight organic acids (LMWOAs) are frequently detected in the aquatic environment and can easily affect the dissolution of manganese oxides, acting as reducing agents and/or chelating agents. A previous study on the oxidation of citrate by $\delta-\mathrm{MnO}_{2}$ shows that dissolved Mn yields S-shaped curve as a function of time,

* Corresponding author: hmguo@cugb.edu.cn. 
indicating that $\mathrm{Mn}(\mathrm{II}) / \mathrm{Mn}(\mathrm{III})$-citrate acid accelerates the reduction of $\delta-\mathrm{MnO}_{2}$ [2]. There are many studies on adsorption and oxidation mechanism of arsenic (As) by manganese oxides [3, 4]. Many researchers have investigated competitive adsorption of dissolved organic matters, like humic acid, in the As- $\mathrm{MnO}_{2}$ system, but have not taken into account the redox roles of LMWOAs in the reaction between manganese oxides and As. The purpose of this study is to gain further insights into the effects of citrate and ethylenediaminetetraacetic acid (EDTA) on oxidation of As(III) and As(V) adsorption by manganese oxide and provide the theoretical basis for the transformation mechanism of arsenic in the environment.

\section{Materials and Methods}

Nanoflower-like manganese oxide was prepared by a facile hydrothermal reaction as described by Hou et al. [5]. As(III) oxidation and $\mathrm{As}(\mathrm{V})$ adsorption experiments were conducted at $25^{\circ} \mathrm{C}$. Batch experiments were performed by suspending $0.03 \mathrm{~g}$ manganese oxide in $50 \mathrm{~mL}$ arsenic solution for $24 \mathrm{~h}$. For reactions involving LMWOAs, $0.03 \mathrm{~g}$ citrate or EDTA was added in the beginning. An aliquot of about $2 \mathrm{~mL}$ of suspension was taken and immediately filtered through a $0.22 \mu \mathrm{m}$ membrane at different time intervals $(30,60$, $180,360,540,720,1080,1440 \mathrm{~min})$ to investigate the kinetics of oxidation and adsorption. Duplicate experiments were conducted.

\section{Results and Discussion}

\subsection{Effect of LMWOAs on As(V) adsorption}

Fig. 1a shows different equilibrium time of $\mathrm{As}(\mathrm{V})$ adsorption. Two stages (before and after equilibrium) were obtained for experiments without organic matter and with EDTA amendment, while three stages (before equilibrium of $\mathrm{As}(\mathrm{V})$ adsorption, between equilibrium of $\mathrm{As}(\mathrm{V})$ adsorption and $\mathrm{Mn}$ dissolution, after equilibrium of $\mathrm{Mn}$ dissolution) for experiments with citrate. Without organic matter, $\mathrm{As}(\mathrm{V})$ adsorption reaches equilibrium in $30 \mathrm{~min}$. Due to the reduction of manganese oxide by citrate, new active sites are created, and $\mathrm{As}(\mathrm{V})$ concentration continues to decrease after $30 \mathrm{~min}$. As(V) adsorption in citrateamending batches reaches equilibrium at around $180 \mathrm{~min}$. As the reaction proceeds, dissolved Mn concentration continues increasing (Fig. 1b), while As(V) concentration remains unchanged, indicating a complicated dynamic balance between desorption of $\mathrm{As}(\mathrm{V})$ caused by manganese dissolution and the competitive adsorption of citrate/ Mn(II)citrate and adsorption of $\mathrm{As}(\mathrm{V})$ is achieved. In the later stage, desorption of $\mathrm{As}(\mathrm{V})$ is partially due to the decrease of surface sites of manganese oxide. EDTA contains more carboxyl groups, and it can promote the dissolution of manganese oxide and create new sites more quickly [6], adsorption of $\mathrm{As}(\mathrm{V})$ continues in the system until $360 \mathrm{~min}$. 

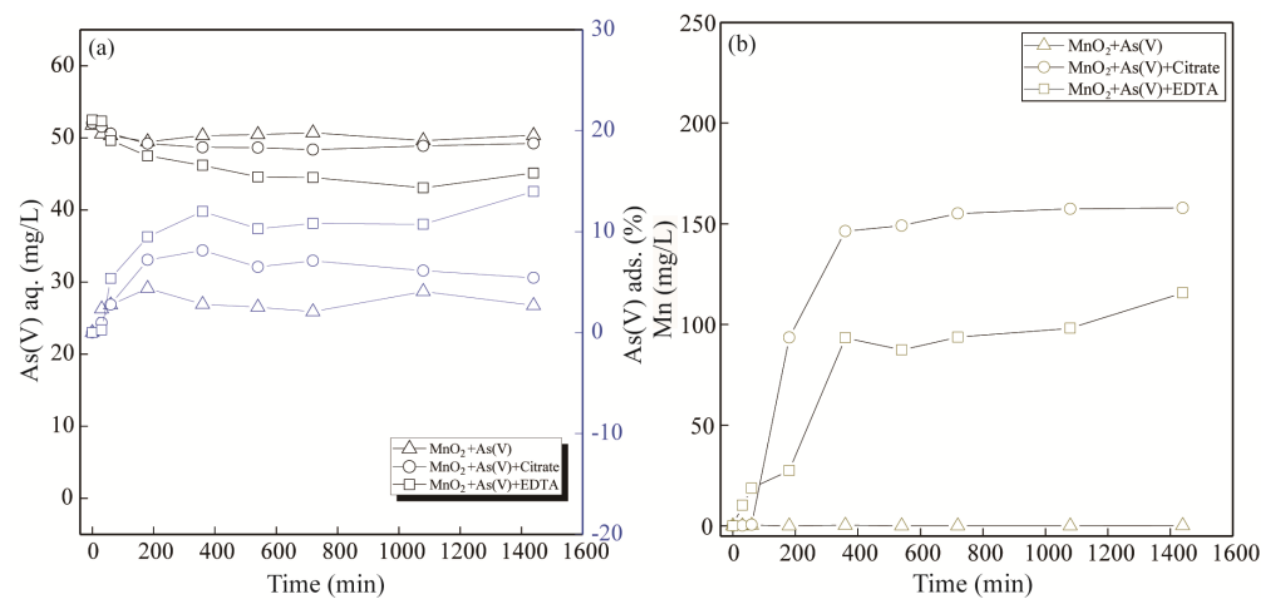

Fig. 1. Concentrations of $A s(V)$ and adsorption percentage (a) and dissolved Mn (b) from experiments reacting $50 \mathrm{mg} / \mathrm{L}$ As $(\mathrm{V})$ with $0.6 \mathrm{~g} / \mathrm{L}$ manganese oxide for $24 \mathrm{~h}$.

\subsection{Effect of LMWOAs on As(III) oxidation}

In As(III) adsorption experiments, LMWOAs affect not only adsorption but also the oxidation process. There are three clear As(III) oxidation stages in the three experiments (Fig. 2a). In the first stage, total As concentration quickly reaches equilibrium in $60 \mathrm{~min}$. Then, As(III) oxidation rate decreases gradually. In the third stage, As(III) concentration reaches equilibrium around $1440 \mathrm{~min}$.
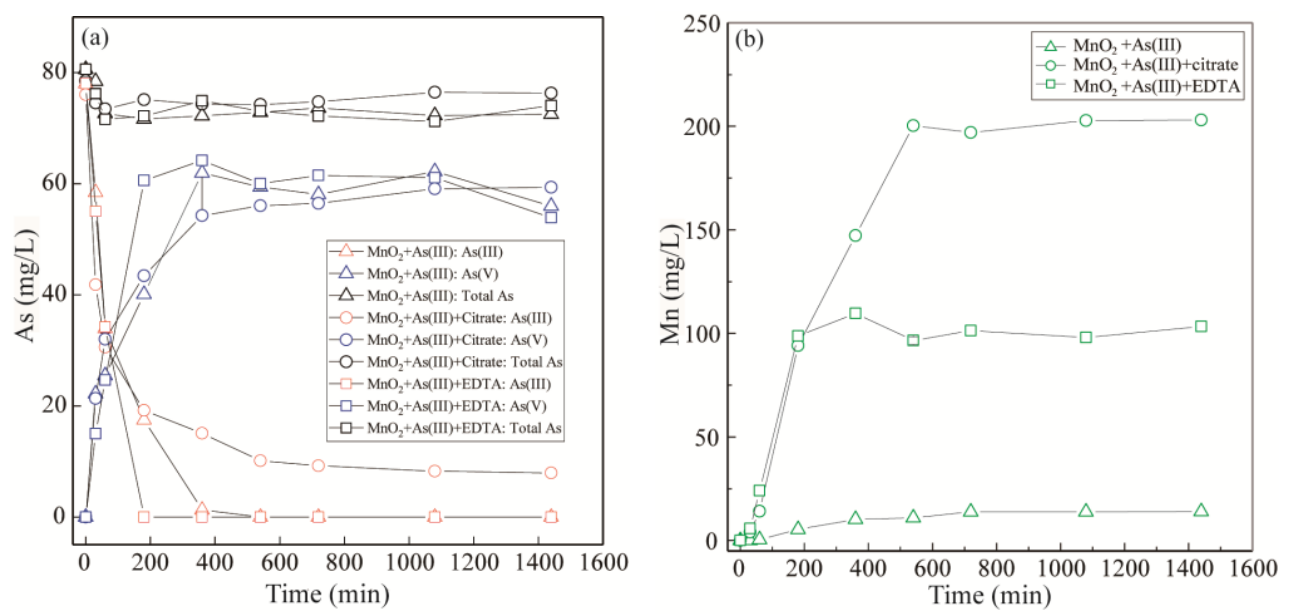

Fig. 2. Concentrations of $\mathrm{As}(\mathrm{III}), \mathrm{As}(\mathrm{V})$ and total As (a) and dissolved Mn (b) from experiments reacting $80 \mathrm{mg} / \mathrm{L} \mathrm{As}(\mathrm{III})$ with $0.6 \mathrm{~g} / \mathrm{L}$ manganese oxide for $24 \mathrm{~h}$.

During the first stage, citrate and EDTA have no significant effect on the adsorption and oxidation process of $\mathrm{As}(\mathrm{III})$, but re-adsorption of $\mathrm{As}(\mathrm{V})$ is inhibited by the adsorption of free citrate on active sites. According to the variations in concentration of dissolved $\mathrm{Mn}$ (Fig. 2b), it can be concluded that citrate and $\mathrm{Mn}(\mathrm{II})$-citrate lower the adsorption of $\mathrm{As}(\mathrm{V})$. EDTA promotes the dissolution of manganese oxide, providing new sites to counteract the influence of competitive adsorption. 
After $60 \mathrm{~min}$, when the rate of As(III) oxidation decreases and a large amount of dissolved $\mathrm{Mn}$ is detected, As(III) oxidation enters the second stage. During this stage, citrate inhibits As(III) oxidation, while EDTA promotes the oxidation, and there is no change in total As concentration. In this stage, manganese oxide becomes passive and $\mathrm{Mn}^{\mathrm{II} / \mathrm{III}}$-citrate autocatalysis occupy the sorption sites, which decrease the oxidation rate. In addition to more news sites created by the reduction of manganese oxide by EDTA, the complexation between EDTA and Mn(II/III) formed by the As-Mn reaction also promotes the oxidation rate of $\mathrm{As}(\mathrm{III})$ by decreasing the competitive adsorption of $\mathrm{Mn}$ (II) onto active sites [7].

After As(III) oxidation reaches equilibrium, the increase in total As concentration in citrate-amended batches may be due to the partial desorption of $\mathrm{As}(\mathrm{V})$.

\section{Conclusion}

In summary, LMWOAs enhances the adsorption of $\mathrm{As}(\mathrm{V})$ on manganese oxide via creating more sorption sites. Citrate inhibits As(III) oxidation, which results from $\mathrm{Mn}^{\mathrm{III} / \mathrm{II}}$ citrate autocatalysis, while reduction of manganese oxide by EDTA and chelation between $\mathrm{Mn}$ (II) and EDTA slightly increase As(III) oxidation rate.

This work provides us a novel insight into the effects of organic matter on As mobilization. LMWOAs can influence As mobility through not only competitive adsorption but also the redox reaction between As and minerals.

The study was financially supported by National Natural Science Foundation of China (Nos. 41672225 and 41825017), the program of China Geology Survey (No. 12120113103700), the Fundamental Research Funds for the Central Universities (No. 2652013028), and the Fok Ying-Tung Education Foundation, China (Grant No. 131017).

\section{References}

1. W. Zhao, H. Cui, F. Liu, W. Tan, X. Feng, Clay. Clay. Min. 57 (2009)

2. Y. Wang, A.T. Stone, Geochim. Cosmochim. Acta. 70 (2016)

3. B.J. Lafferty, M. Gindervogel, D.L. Sparks, Environ. Sci. Technol. 44 (2010)

4. C. Tournassat, L. Charlet, D. Bosbach, Environ. Sci. Technol. 36 (2002)

5. J. Hou, Y. Li, M. Mao, L. Ren, X. Zhao, ACS Appl. Mater. Interf. 6 (2014)

6. X. Huangfu, J. Jiang, J. Ma, Y. Wang, Y. Liu, Colloid Surf. A-Physicochem. Eng. Asp. 482 (2015)

7. B.J. Lafferty, M. Ginder-Vogel., M. Zhu, K.J.T. Livi, D.L. Sparks, Environ. Sci. Technol. 44 (2010) 